\title{
The Antioxidant Capacity of Rosemary and Green Tea Extracts to Replace the Carcinogenic Antioxidant (BHA) in Chicken Burgers
}

\author{
Manoela A. Pires, ${ }^{1}$ Paulo E. S. Munekata, ${ }^{1}$ Nilda D. M. Villanueva, \\ Fernando G. Tonin, ${ }^{3}$ Juliana C. Baldin, ${ }^{1}$ Yana J. P. Rocha, ${ }^{1}$ \\ Larissa T. Carvalho, ${ }^{1}$ Isabela Rodrigues, ${ }^{1}$ and Marco A. Trindade ${ }^{1}$ \\ ${ }^{1}$ Department of Food Engineering, College of Animal Science and Food Engineering, University of São Paulo (FZEA/USP), \\ 225 Duque de Caxias Norte Av., Jardim Elite, 13.635-900 Pirassununga, SP, Brazil \\ ${ }^{2}$ Facultad de Ingeniería Agraria, Universidad Católica Sedes Sapientiae, Esq. Constelaciones y Sol de Oro S/N, \\ Urb. Sol de Oro, Los Olivos, Lima, Peru \\ ${ }^{3}$ Department of Biosystems Engineering, College of Animal Science and Food Engineering, University of São Paulo (FZEA/USP), \\ 225 Duque de Caxias Norte Av., Jardim Elite, 13.635-900 Pirassununga, SP, Brazil
}

Correspondence should be addressed to Manoela A. Pires; manoela.pires@usp.br

Received 6 July 2016; Revised 21 October 2016; Accepted 16 November 2016; Published 22 January 2017

Academic Editor: Jorge Barros-Velázquez

Copyright (C) 2017 Manoela A. Pires et al. This is an open access article distributed under the Creative Commons Attribution License, which permits unrestricted use, distribution, and reproduction in any medium, provided the original work is properly cited.

\begin{abstract}
The present study aimed to evaluate the effect of natural extracts (rosemary and green tea extracts) in frozen storage of chicken burgers. Chicken burger treatments were prepared as follows: control (CON), $20 \mathrm{mg}$ BHA/kg (BHA20), $10 \mathrm{mg}$ green tea extract $/ \mathrm{kg}$ (GT10), $38 \mathrm{mg}$ green tea extract/kg (GT38), $18.6 \mathrm{mg}$ rosemary extract/kg (RO18), and $480 \mathrm{mg}$ rosemary extract/kg (RO480). Analysis of physicochemical parameters, color, TBAR index, and sensory acceptance were performed at $0,30,60$, and 120 days of storage at $-18^{\circ} \mathrm{C}$ in burgers packaged in LDPE plastic bags. The addition of natural antioxidants did not affect $(p>0.05)$ the color and physicochemical parameters of the chicken burgers. After 120 days at $-18^{\circ} \mathrm{C}$, the RO480 sample showed a TBAR index similar $(p>0.05)$ to BHA20 (0.423 and $0.369 \mathrm{mg}$, resp.). Sensory acceptance did not differ $(p>0.05)$ among the treatments throughout the storage period ( $p>0.05)$.
\end{abstract}

\section{Introduction}

Synthetic food additives, such as butyl hydroxyl anisole (BHA), are normally used by the food industry in order to control lipid oxidation, although these compounds are considered toxic to human health [1-3]. At the present time, much investigative research is being carried out to replace carcinogenic antioxidants, mainly in processed meat. A recent study suggested that processed meats could be carcinogenic [4] or that chemical contaminants could be added to meat products [5]. Kumar et al. [6] confirmed this in the review "Toxicological and Carcinogenic Effects of Synthetic Antioxidants." For this reason, natural extracts with antioxidant potential can be a valuable alternative to synthetic compounds.

Herbs and spices such as rosemary and green tea are effective protectors against oxidation due to their antioxidant capacity [7]. The ability to inhibit oxidation is associated with the chemical structure of phenolic compounds that are similar to chemical antioxidants. Efficiency of natural extracts in food systems depends on factors such as the chemical reactivity of their constituents, extraction procedure, and interaction with food components [8]. The main studies about plant extracts are related to quantification of antioxidant compounds in order to identify the potential in antioxidant mechanisms [7]. In general, plants, herbs, 
TABLE 1: Antioxidant capacity values according to the different methodologies.

\begin{tabular}{lccc}
\hline Sample & Folin-Ciocalteu $(\mathrm{mg} \mathrm{GAE} / \mathrm{g})$ & FRAP $(\mu \mathrm{mol} \mathrm{Trolox} / \mathrm{g})$ & $\mathrm{EC}_{50}(\mathrm{mg} / \mathrm{L})$ \\
\hline BHA & $1476.67 \pm 33.00^{\mathrm{a}}$ & $3327.32 \pm 202.15^{\mathrm{a}}$ & $24.13 \pm 0.018^{\mathrm{a}}$ \\
Rosemary extract (4.4\% phenolics) & $114.50 \pm 0.24^{\mathrm{b}}$ & $140.88 \pm 4.08^{\mathrm{b}}$ & $22.46 \pm 0.025^{\mathrm{a}}$ \\
Pure rosemary extract (supposed value) & 2602.27 & 3201.82 & 0.98 \\
Green tea extract (20\% diterpenes) & $1497.97 \pm 19.88^{\mathrm{a}}$ & $1757.96 \pm 47.14^{\mathrm{c}}$ & $11.70 \pm 0.017^{\mathrm{b}}$ \\
Pure green tea extract (supposed value) & 7489.85 & 8789.80 & 2.34 \\
\hline
\end{tabular}

Results are expressed as mean value \pm standard deviation $(n=3)$. Different letters indicate significant difference (estimated by ANOVA analysis and Tukey's test, $p \leq 0.05)$.

and fruits are known to contain a wide variety of phytochemicals, such as polyphenols, carotenoids, flavonoids, and catechins [9]. These products could be natural antioxidants because the compounds could scavenge free radicals and provide oxidative stability to many food items including high fat meat products [10]. The mechanism involved in the antioxidant activity of either natural or synthetic antioxidants is dependent on molecular structure. Additional galloyl, catechoyl, or hydroxyl groups in phenolic compounds have been associated with an increase in antioxidant activity [11].

There are now several methods of quantifying the antioxidant activity of natural extracts but none of them are considered official because the matrix of each method presents different reaction system and complexity; for example, the total polyphenol method is based on the Folin-Ciocalteu reagent, and the FRAP assay is based on the reduction of ferric ions under acidic conditions. These studies have evaluated only the antioxidant activity without concern as to whether it represents the same performance in the food matrix, for example, meat products. Meat is susceptible to oxidation; in particular, chicken meat is more susceptible than other meats due to having more unsaturation lipids in its lipid structure [12-14].

Therefore, the aim of this study was to evaluate potential replacements of BHA (synthetic antioxidant) in frozen chicken burgers. For this purpose, the antioxidant potential of all the antioxidants tested (natural and synthetic) was determined and the concentration of natural antioxidants was also defined from these results. The color and physicalchemical and lipid stability of the chicken burgers were also evaluated.

\section{Material and Methods}

2.1. Chemicals and Raw Material. The synthetic and natural antioxidants employed in the evaluation were obtained from Dupont $^{\mathrm{TM}}$ Danisco, Brazil [BHA pure synthetic antioxidant, rosemary extract (Rosmarinus officinalis L.) containing $4.4 \%$ phenolic diterpenes and green tea extract (Camellia sinensis) containing $20 \%$ of catechins]. Chicken meat and spices were purchased from the local market.

2.2. Estimation of Total Polyphenol Content. The activity of the antioxidants was assessed by analysis of reducing power measured with the Folin-Ciocalteu reagent described by Singleton and Rossi [15] and Georgé et al. [16] and evaluated at $760 \mathrm{~nm}$ against a blank in absence of extract in a spectrophotometer SP-22 (Biospectro, Brazil). The values were expressed as milligram of gallic acid equivalent per gram of antioxidant (mg GAE/g).

2.3. Ferric Reducing Antioxidant Power (FRAP) Assay. The FRAP method was based on the reduction of the ferric ion $\left(\mathrm{Fe}^{3+}\right)$ to ferrous ion $\left(\mathrm{Fe}^{2+}\right)$ under acidic conditions [17]. It was quantified at $593 \mathrm{~nm}$ after $30 \mathrm{~min}$. and expressed as $\mu \mathrm{mol}$ Trolox equivalent per gram of antioxidant (TE/g).

\subsection{Determination of Antioxidant Capacity: Free Radical Scav-} enging Using the DPPH Radical. The free radical scavenging capacity of antioxidants was measured using stable $\mathrm{DPPH}^{\circ}$ as previously described [18]. The absorbance (Abs) was measured at $515 \mathrm{~nm}$ until the end point time, approximately 3 hours, determined in studies to prove the sample's stability [19]. The percentage of DPPH inhibition was calculated according to the formula: DPPH inhibition $(\%)=[(\mathrm{Abs}$ control - Abs sample)/Abs control] $\times 100$ and results were expressed in $\mathrm{EC}_{50}(\mathrm{mg} / \mathrm{L}$ of antioxidant).

2.5. Manufacture of Chicken Patties and Sampling Procedures. All batches of chicken burgers were prepared using the same formulation: $75 \%$ of chicken breast, $20 \%$ of chicken skin (both minced in a $3 \mathrm{~mm}$ plate using a meat mincer), $1.23 \%$ condiments (salt and white pepper), and water and antioxidant according to each treatment. The samples were packaged in low density polyethylene (LDPE) plastic bags and stored at $-18 \pm 1^{\circ} \mathrm{C}$ for 4 months.

Four different dosages of the natural antioxidants were determined according to the results of antioxidant capacity analyses (FRAP and DPPH) (Table 1) based on the maximum permitted level of BHA according to Brazilian legislation $(100 \mathrm{mg} / \mathrm{kg})$ regarding fat content in the meat product, therefore, $20 \mathrm{mg} / \mathrm{kg}$ BHA [20] (taking 20\% chicken skin into account). Dosages of natural extracts were calculated according to the following example: in the analysis of green tea extract by the FRAP method, the result was $1757.96 \mu \mathrm{mol} \mathrm{TE} / \mathrm{g}$, whereas the BHA was $3327.32 \mu \mathrm{mol}$ Trolox/g. The following inverse rule of three was then considered: $(1757.96 / 3327.32)=(100 \% / x), x=189.27 \%$. From this, it was determined that to obtain the same capacity of the antioxidant BHA, the green tea extract should be dosed at $89.27 \%$ more than the synthetic. That is, $89.27 \% \times 0.002$ $($ BHA concentration $)=0.0038 \%(38 \mathrm{mg} / \mathrm{kg})$. The concentration of green tea extract was also determined considering the DPPH radical assay following a similar calculation 
applied to the FRAP assay which resulted in $10 \mathrm{mg} / \mathrm{kg}$. Rosemary extract concentrations based on the FRAP and DPPH radical assays were also calculated and indicated 480 and $18.6 \mathrm{mg} / \mathrm{kg}$, respectively. However, once the dosages prescribed by the Folin-Ciocalteu method showed intermediate values between the FRAP and DPPH, they were disregarded. After determination of the antioxidant dosages, the following six treatments were assigned: control (without antioxidant), BHA20 (20 mg BHA/kg), GT38 (38 mg green tea extract $/ \mathrm{kg}$ ), GT10 (10 mg green tea extract $/ \mathrm{kg}$ ), RO480 (480 mg rosemary extract $/ \mathrm{kg}$ ), and RO18 (18.6 $\mathrm{mg}$ rosemary $/ \mathrm{kg}$ ).

2.6. Proximate Composition, $\mathrm{pH}$, and Color of Burgers. The proximate composition of uncooked burgers was analyzed as follows: the moisture content was determined by drying in an oven at a temperature of $105^{\circ} \mathrm{C}$ for about 24 hours until constant weight was obtained (950.46 [21]). The amount of ash and mineral content was determined with the residue obtained in moisture and placed in an oven at $550^{\circ} \mathrm{C}$ for approximately 96 hours at constant weight (AOAC 920153 [21]). The protein determination was performed according to the Kjeldahl method, according to AOAC 981.10 [21]. Lipid content was determined according to Bligh and Dyer [22].

Value of $\mathrm{pH}$ was determined by pHmetro Hanna and meat color measurements were made using a colorimeter (mod. MiniScan XE, Hunterlab brand) in which the equipment was calibrated with a standard white and another black pattern in the CIE system. Evaluating measures absolute coordinates of brightness $\left(L^{*}\right)$, red color $\left(a^{*}\right)$, and yellow $\left(b^{*}\right)$.

2.7. Evaluation of Oxidative Stability and Sensory Analysis. Stability of the burgers during the frozen storage $\left(-18 \pm 1^{\circ} \mathrm{C}\right)$ was monitored at zero, 30,60, 90, and 120 days, respectively, applying the thiobarbituric acid-reactive substances (TBARS) method and sensory evaluation. TBAR assay was performed as described by Vyncke [23]. Absorbance was read at $538 \mathrm{~nm}$ and values are expressed as $\mathrm{mg}$ of TBARS per $\mathrm{kg}$ of meat (TBAR index). For sensory evaluation, the burgers were cooked on an electric griddle (Croydon, GRSE 20665-6, Brazil) at $165^{\circ} \mathrm{C}$ for 4 minutes on each side, until internal center temperature reached $90^{\circ} \mathrm{C}$, as measured by a thermocouple. Samples were evaluated by 60 regular chicken burger consumers, for "general acceptability" using a ninepoint hedonic scale, varying from " $1=$ dislike extremely" to "9 = like extremely," according to Meilgaard et al. [24].

2.8. Statistical Analysis. Experimental data were analyzed using repeated measures ANOVA ( $p \leq 0.05$ ), considering the repeated measures factor and the five levels of storage time. The comparisons of treatment averages and storage time averages were performed using the Tukey HSD test $(p \leq$ 0.05 ). Two replicates were performed for each treatment at each storage time. All statistical analyses were performed using the Statistica ${ }^{\mathrm{TM}}$ software (Statsoft Inc., Tulsa, OK).

\section{Results}

3.1. Proximate Composition, $\mathrm{pH}$, and Color. In all treatments, moisture, fat, and protein content met the standards set by current Brazilian legislation for this type of meat product [25] which should not exceed $23 \%$ of lipids and contain at least $15 \%$ protein. The average of results was moisture $68.99 \pm 0.66 \%$, protein $18.53 \pm 0.20 \%$, fat $9.07 \pm 0.31 \%$, and ash $2.21 \pm 0.07 \%$.

The $\mathrm{pH}$ values did not differ $(p>0.05)$ among all samples and were close to 6.00 , indicating that the $\mathrm{pH}$ samples were not influenced by the addition of different antioxidants. Similar values were found by Trindade et al. [26] in MSM (mechanically separated meat) chicken with antioxidants during frozen storage.

ANOVA results for the $L^{*}, a^{*}$, and $b^{*}$ parameters did not differ significantly, neither between treatments nor over time $(p>0.05)$. The average $L^{*}$ values were between 45.91 and 51.14 and the $b^{*}$ values between 4.88 and 7.00. The $L^{*}$ values observed in the present study were in accordance with the results obtained by Yogesh and Ali [10]. These authors studied the effect of Thuja occidentalis and Prunus persica natural antioxidants in ground chicken meat and found $L^{*}$ values around 48.2. Concerning $b^{*}$, the researchers obtained a different value around 20.0, which could be because of the type and quality of the raw meat material and the country of production. For the $a^{*}$ parameter, the values are close to zero, indicating that chicken burgers present a less intense red color compared with other meats, which would be expected.

3.2. Antioxidant Capacity. There was no significant difference in antioxidant capacity between green tea and BHA evaluated by the Folin-Ciocalteu method (Table 1). However, rosemary presented a lower value $(p \leq 0.05)$ compared with other antioxidants. A possible explanation for this behavior is the quantity of phenols contained in each extract and their different antioxidant mechanisms. Erkan et al. [27] analyzed rosemary extract and found that it contained $6 \%$ carnosic and $8 \%$ rosmarinic acids. They affirmed that there are different phenolic diterpenes in rosemary extracts and that these components could explain the antioxidant activity of natural extracts.

Values from the FRAP assay indicated that the three antioxidants have different antioxidant capacities $(p \leq 0.05)$, with higher values for BHA and then the other two natural extracts, with rosemary the lowest. High value of antioxidant capacity of BHA was also reported by Hossain et al. [28].

$\mathrm{DPPH}^{\circ}$ values of rosemary and BHA (expressed as EC50 on Table 1) were superior to green tea $(p \leq 0.05)$ which therefore showed the lowest antioxidant capacity, for the $\mathrm{DPPH}^{\circ}$ radical assay is based on the decrease of $\mathrm{DPPH}^{\circ}$ radical absorbance. A possible explanation for this is that, in this present study, 3 hours was necessary to reach an absorbance plateau for extracts exposed to light and heat in a bath at $25^{\circ} \mathrm{C}$, which may have affected the result since some extracts are more sensitive to these conditions than others [29].

Similar $\mathrm{EC}_{50}$ values of BHA were observed by BubonjaSonje et al. [30], and Duarte-Almeida et al. [31] obtained $28.20 \mathrm{mg} / \mathrm{L}$ and $25.00 \mathrm{mg} / \mathrm{L}$, respectively.

In fact, the antioxidant activity of different extracts is directly related to the concentration of active components, which, in this present study, was $4 \%$ in the rosemary extract and $20 \%$ in the green tea extract. Thus, if the antioxidant 
TABLE 2: Results of sensory acceptance of chicken burgers during storage period.

\begin{tabular}{lccccc}
\hline Treatments & \multicolumn{3}{c}{ Storage time (days) } \\
& 0 & 30 & 60 & $7.0 \pm 1.38$ & $7.0 \pm 1.52$ \\
Control & $7.0 \pm 1.47$ & $6.6 \pm 1.55$ & $6.8 \pm 1.51$ & $6.6 \pm 1.43$ & $6.8 \pm 1.36$ \\
BHA20 & $7.2 \pm 1.43$ & $6.8 \pm 1.47$ & $7.1 \pm 1.22$ & $6.7 \pm 1.19$ & $6.8 \pm 1.50$ \\
GT38 & $7.0 \pm 1.55$ & $6.9 \pm 1.53$ & $6.8 \pm 1.21$ & $6.7 \pm 1.32$ & $6.7 \pm 1.48$ \\
GT10 & $7.2 \pm 1.25$ & $6.7 \pm 1.40$ & $7.2 \pm 1.18$ & $6.7 \pm 1.47$ & $6.5 \pm 1.61$ \\
RO480 & $6.7 \pm 1.34$ & $6.6 \pm 1.64$ & $6.8 \pm 1.35$ & $6.8 \pm 1.32$ & $6.9 \pm 1.14$ \\
RO18 & $7.1 \pm 1.34$ & $7.0 \pm 1.39$ & $6.9 \pm 1.34$ \\
\hline
\end{tabular}

Results are expressed as mean value \pm standard deviation. Averages showed no difference $(p \geq 0.05)$ by ANOVA test.

potential of both extracts is evaluated and compared with the pure synthetic antioxidant (100\%), we can assume that the natural extracts have a higher antioxidant activity than the synthetic, as shown in Table 1 (supposed values for pure extracts). According to Wojdyło et al. [32], the antioxidant potential of phenolics depends on a number of factors, such as their skeleton structure and pattern of functional groups on this skeleton. To extract the total phenolics of natural substrates is critical due to phenolic derivatives, because polyphenols constitute one of the most numerous groups of phenolic structures and the chemical diversity of antioxidants makes it difficult to extract [33].

From this point of view, Soobrattee et al. [33] affirmed that it is critical to evaluate antioxidant activity only in vitro. They confirmed that it is essential to evaluate the behavior of antioxidants at different points. In this present study the antioxidants were evaluated in terms of potential interacting with a specific target molecule (diluted in an aqueous compound) and applied directly in food structure (burger application). The phenolic compounds may interact with free radicals to delay lipid oxidation which are generated in the initiation phase, propagation phase, or during the breakdown of the hydroperoxides $[6,33]$.

3.3. Oxidative Stability during Frozen Storage. Regarding lipid oxidation determined by the TBARS method, it was observed that there were significant effects of treatment and storage time, showing differences between treatments during storage time $(p \leq 0.05)$.

Initial TBAR values (zero time) showed no differences $(p \geq 0.05)$ between any of the samples (Figure 1). Samples BHT20 and RO480 were more stable in terms of lipid oxidation level over time. In spite of that control, RO18, GT10, and GT38 showed increased lipid oxidation level during storage time, insofar as the control test showed an increase of $65 \%$ in the TBAR index at 120 days. However, the burgers applied with a higher dosage of green tea extract also presented a difference from the control $(p \leq 0.05)$ after 120 days of storage, showing that the higher experimental dosages were effective in order to control the lipid oxidation of samples. These results show the greater effectiveness of rosemary in relation to green tea, since the rosemary extract showed the same efficacy as BHA treatment.
In this present study the TBAR index showed values lower than 1.0, which is extremely important, because high levels of TBAR are toxic, carcinogenic, and mutagenic [34].

3.4. Sensory Stability. Regarding sensory evaluation, the ANOVA results for sensory data indicated that the effect of treatments and storage time were not significant $(p>0.05)$, showing that the addition of natural extracts (rosemary and green tea) at any tested concentration did not affect consumers' sensory acceptance of the chicken burgers (Table 2). O'Neill et al. [35] argue that the rancid flavors in meat are initially detected by assessors in amounts from 0.5 to 2.0 on the TBAR index, which could be a possible explanation for good acceptability in this present study.

3.5. Comparison of TBAR $x$ Antioxidant Capacity Evaluation. Antioxidant extracts were applied in two different concentrations in the burgers, according to the antioxidant capacity analyses of FRAP and DPPH. The concentrations of natural extracts based on the Folin-Ciocalteu method results were not applied to the samples because the results obtained by this method showed intermediate values, between the two other methods, and the number of samples would be excessive to perform oxidation analyses. Calculations were carried out in order to determine whether natural extracts have the same antioxidant capacity as BHA, aiming at the same performance of the natural extracts in relation to BHA in the oxidative stability of chicken burgers. However, this behavior was not observed for all dosages applied. For this reason, it can be concluded that the method to determine the antioxidant capacity is a key factor in determining the dosage of natural antioxidants to replace synthetic antioxidants. Results obtained in this experiment demonstrated that dosages of natural extracts added to chicken burgers as determined by the FRAP method produced a TBAR index quite similar to products with BHA $20 \mathrm{mg} / \mathrm{Kg}$. This can be better observed in Figure 1 mainly for BHA20 and RO480 treatments, which presented a similar pattern throughout the frozen storage period. The three methods used in this study (Folin-Ciocalteu, FRAP, and DPPH) involve electron transfer reaction, which is a reaction involved in the impairment of oxidative reactions. It is worth noting that these methods have different arrays and can directly influence the result of the 


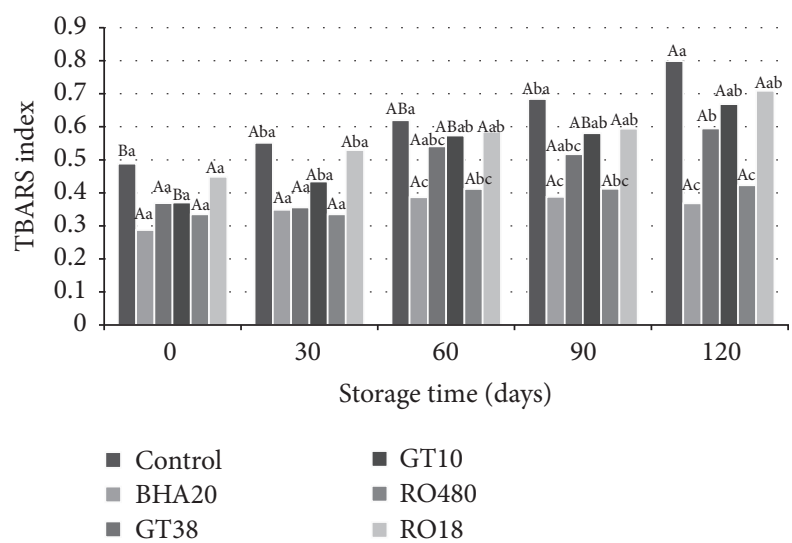

FIGURE 1: TBARS index mean values of chicken burgers treatments during storage period. Each point represents the mean value \pm standard deviation $(n=3)$. For each treatment, averages followed by different capital letters differ significantly $(p \leq 0.05)$ during storage time (see the same treatment during different storage times) and for each storage time, averages followed by different lowercase letters differ significantly per treatment (see the different treatments in the same storage time) $(p \leq 0.05)$ by the Tukey HSD test.

analysis and, therefore, must be dosed in the correct quantity in the final product [36].

According to Huang et al. [7], there is great interest in research to define a convenient method to quantify antioxidant effectiveness. In fact, to measure antioxidant activity in model systems presents several problems to be extrapolated in food products, such as prooxidant effects, the mincing of meat and fat, the presence of salt, and long storage time, versus antioxidant effects, the presence of antioxidant compounds (phenolics), reduced temperature during storage, and polar paradox. The researchers suggested that a general protocol should test various oxidation conditions and compare antioxidants at the same molar concentrations as active components.

There seems to be no consensus of opinion, most probably due to the complexity of the composition of foods and different phenolic compounds. Studying this individually could be costly and inefficient. In fact, the area of antioxidant compounds in a food mixture is an extremely complex topic.

\section{Conclusion}

In conclusion, under the conditions evaluated in this study, commercial rosemary extract can replace the synthetic antioxidant BHA in the proportion of $20 \mathrm{mg} / \mathrm{kg}$ to rosemary at $480 \mathrm{mg} / \mathrm{kg}$ in chicken burgers, assuring its stability during the 4 months of frozen storage, providing a healthier and cleaner label, without changing the sensory acceptance of the product.

\section{Additional Points}

Practical Applications. Concerns about the negative health effects of synthetic antioxidants, like BHA and BHT, widely used by the meat processing industry, have led to research in the food industry seeking alternatives. Natural extracts rich in phenolic compounds from sources already present in the diet are thought to have a central role in this trend. In our study, the effects of two promising natural extracts, rosemary and green tea natural extracts, were studied at two levels in chicken burgers frozen for 120 days. Results pointed to rosemary extract at $480 \mathrm{mg} / \mathrm{kg}$ as a commendable alternative for future industrial applications due to the similar protective effect against lipid oxidation compared to BHA $(20 \mathrm{mg} / \mathrm{kg})$.

\section{Competing Interests}

The authors declare that they have no competing interests.

\section{Acknowledgments}

The authors would like to thank Dupont Danisco for the antioxidant extracts applied in this study.

\section{References}

[1] C. Chen, A. M. Pearson, and J. I. Gray, "Effects of synthetic antioxidants (BHA, BHT and PG) on the mutagenicity of IQlike compounds," Food Chemistry, vol. 43, no. 3, pp. 177-183, 1992.

[2] F. Iverson, "Phenolic antioxidants: health protection branch studies on butylated hydroxyanisole," Cancer Letters, vol. 93, no. 1, pp. 49-54, 1995.

[3] S. Vandghanooni, A. Forouharmehr, M. Eskandani et al., "Cytotoxicity and DNA fragmentation properties of butylated hydroxyanisole," DNA and Cell Biology, vol. 32, no. 3, pp. 98103, 2013.

[4] V. Bouvard, D. Loomis, K. Z. Guyton et al., "Carcinogenicity of consumption of red and processed meat," The Lancet Oncology, vol. 16, no. 16, pp. 1599-1600, 2015.

[5] J. L. Domingo and M. Nadal, "Carcinogenicity of consumption of red and processed meat: what about environmental contaminants?" Environmental Research, vol. 145, pp. 109-115, 2016.

[6] Y. Kumar, D. N. Yadav, T. Ahmad, and K. Narsaiah, "Recent trends in the use of natural antioxidants for meat and meat products," Comprehensive Reviews in Food Science and Food Safety, vol. 14, no. 6, pp. 796-812, 2015.

[7] D. Huang, B. Ou, and R. L. Prior, "The chemistry behind antioxidant capacity assays," Journal of Agricultural and Food Chemistry, vol. 53, no. 6, pp. 1841-1856, 2005.

[8] E. L. Ferreira, G. R. Sampaio, E. A. Torres, and D. H. Bastos, "Natural antioxidant from yerba maté (Ilex paraguariensis St. Hil.) prevents hamburger peroxidation," Brazilian Archives of Biology and Technology, vol. 54, no. 4, pp. 802-809, 2011.

[9] R. H. Liu, "Health benefits of fruits and vegetables are from additive and synergistic combination of phytochemicals," The American Journal of Clinical Nutrition, vol. 78, pp. 517S-520S, 2003.

[10] K. Yogesh and J. Ali, "Antioxidant potential of thuja (Thuja occidentalis) cones and peach (Prunus persia) seeds in raw chicken ground meat during refrigerated $(4 \pm 1 \circ \mathrm{C})$ storage," Journal of Food Science and Technology, vol. 51, no. 8, pp. 15471553, 2014.

[11] C. D. Capitani, A. C. L. Carvalho, D. P. Rivelli, S. B. M. Barros, and I. A. Castro, "Evaluation of natural and synthetic compounds according to their antioxidant activity using a 
multivariate approach," European Journal of Lipid Science and Technology, vol. 111, no. 11, pp. 1090-1099, 2009.

[12] T. D. Drumm and A. M. Spanier, "Changes in the content of lipid autoxidation and sulfur-containing compounds in cooked beef during storage," Journal of Agricultural and Food Chemistry, vol. 39, no. 2, pp. 336-343, 1991.

[13] L. D. Shirahigue, C. J. Contreras-Castillo, M. M. Selani, A. P. Nadai, G. B. Mourão, and C. R. Gallo, "Winery grape-residue extract: effects on quality and sensory attributes of cooked chicken meat," Food Science and Biotechnology, vol. 20, no. 5, pp. 1257-1264, 2011.

[14] Z. F. Bhat, P. Kumar, and S. Kumar, "Effect of skin, enrobing and refrigerated storage on the quality characteristics of chicken meat balls," Journal of Food Science and Technology, vol. 50, no. 5, pp. 890-899, 2013.

[15] V. L. Singleton and J. A. Rossi, "Colorimetry of total phenolics with phosphomolybdic-phosphotungstic acid reagents," American Journal of Enology and Viticulture, vol. 16, pp. 144-158, 1965.

[16] S. Georgé, P. Brat, P. Alter, and M. J. Amiot, "Rapid determination of polyphenols and vitamin C in plant-derived products," Journal of Agricultural and Food Chemistry, vol. 53, no. 5, pp. 1370-1373, 2005.

[17] I. F. F. Benzie and J. J. Strain, "The ferric reducing ability of plasma (FRAP) as a measure of 'antioxidant power': the FRAP assay," Analytical Biochemistry, vol. 239, no. 1, pp. 70-76, 1996.

[18] W. Brand-Williams, M. E. Cuvelier, and C. Berset, "Use of a free radical method to evaluate antioxidant activity," LWT-Food Science and Technology, vol. 28, no. 1, pp. 25-30, 1995.

[19] R. P. P. Fernandes, M. A. Trindade, F. G. Tonin et al., "Evaluation of antioxidant capacity of 13 plant extracts by three different methods: cluster analyses applied for selection of the natural extracts with higher antioxidant capacity to replace synthetic antioxidant in lamb burgers," Journal of Food Science and Technology, vol. 53, no. 1, pp. 451-460, 2016.

[20] BRASIL, "Ministério da Saúde, Conselho Nacional de Saúde. Resolução nº4, de 24 de novembro de 1988; Aprovar a revisão das Tabelas I, III, IV e V referente a Aditivos Intencionais do Decreto n55.871, de 26 de março de 1965, publicada no Diário Oficial da União, Brasília, DF, 19 dez. 1988. Seção 1".

[21] Association of Official Analytical Chemists (AOAC), Official Methods of Analysis of AOAC International, AOAC, Gaithersburg, Md, USA, 18th edition, 2007.

[22] E. G. Bligh and W. J. Dyer, "A rapid method of total lipid extraction and purification," Canadian Journal of Biochemistry and Physiology, vol. 37, no. 8, pp. 911-917, 1959.

[23] W. Vyncke, "Evaluation of the direct thiobarbituric acid extraction method for determining oxidative rancidity in mackerel (Scomber scombrus L.)," Fette, Seifen, Anstrichmittel, vol. 77, no. 6, pp. 239-240, 1975.

[24] M. C. Meilgaard, G. V. Civille, and B. T. Carr, Sensory Evaluation Techniques, CRC Press, Boca Raton, Fla, USA, 1991.

[25] BRASIL, "Instrução Normativa MAPA no 51, de 29 de dezembro de 2006," Diário Oficial [da] República Federativa do Brasil, Brasília, DF, 4 jan. 2007.

[26] M. A. Trindade, T. P. Nunes, C. J. Contreras-Castillo, and P. E. De Felício, "Oxidative and microbiological stability of mechanically separated hen meat pre blended with antioxidants during frozen storage," Ciência e Tecnologia de Alimentos, vol. 28, no. 1, pp. 160-168, 2008.

[27] N. Erkan, G. Ayranci, and E. Ayranci, "Antioxidant activities of rosemary (Rosmarinus Officinalis L.) extract, blackseed (Nigella sativa L.) essential oil, carnosic acid, rosmarinic acid and sesamol," Food Chemistry, vol. 110, no. 1, pp. 76-82, 2008.

[28] M. B. Hossain, C. Barry-Ryan, A. B. Martin-Diana, and N. P. Brunton, "Effect of drying method on the antioxidant capacity of six Lamiaceae herbs," Food Chemistry, vol. 123, no. 1, pp. 8591, 2010.

[29] M. S. Brewer, "Natural antioxidants: sources, compounds, mechanisms of action, and potential applications," Comprehensive Reviews in Food Science and Food Safety, vol. 10, no. 4, pp. 221-247, 2011.

[30] M. Bubonja-Sonje, J. Giacometti, and M. Abram, "Antioxidant and antilisterial activity of olive oil, cocoa and rosemary extract polyphenols," Food Chemistry, vol. 127, no. 4, pp. 1821-1827, 2011.

[31] J. M. Duarte-Almeida, R. J. Santos, M. I. Genovese, and F. M. Lajolo, "Avaliação da atividade antioxidante utilizando sistema $\beta$-caroteno/ácido linoleico e método de sequestro de radicais DPPH," Ciência e Tecnologia de Alimentos, vol. 26, no. 2, pp. 446-452, 2006.

[32] A. Wojdyło, J. Oszmiański, and R. Czemerys, "Antioxidant activity and phenolic compounds in 32 selected herbs," Food Chemistry, vol. 105, no. 3, pp. 940-949, 2007.

[33] M. A. Soobrattee, V. S. Neergheen, A. Luximon-Ramma, O. I. Aruoma, and T. Bahorun, "Phenolics as potential antioxidant therapeutic agents: mechanism and actions," Mutation Research-Fundamental and Molecular Mechanisms of Mutagenesis, vol. 579, no. 1-2, pp. 200-213, 2005.

[34] S. Z. Tang, J. P. Kerry, D. Sheehan, D. J. Buckley, and P. A. Morrissey, "Antioxidative effect of dietary tea catechins on lipid oxidation of long-term frozen stored chicken meat," Meat Science, vol. 57, no. 3, pp. 331-336, 2001.

[35] L. M. O’Neill, K. Galvin, P. A. Morrissey, and D. J. Buckley, "Comparison of effects of dietary olive oil, tallow and vitamin E on the quality of broiler meat and meat products," British Poultry Science, vol. 39, no. 3, pp. 365-371, 1998.

[36] M. G. Miguel, "Antioxidant activity of medicinal and aromatic plants. A review," Flavour and Fragrance Journal, vol. 25, no. 5, pp. 291-312, 2010. 

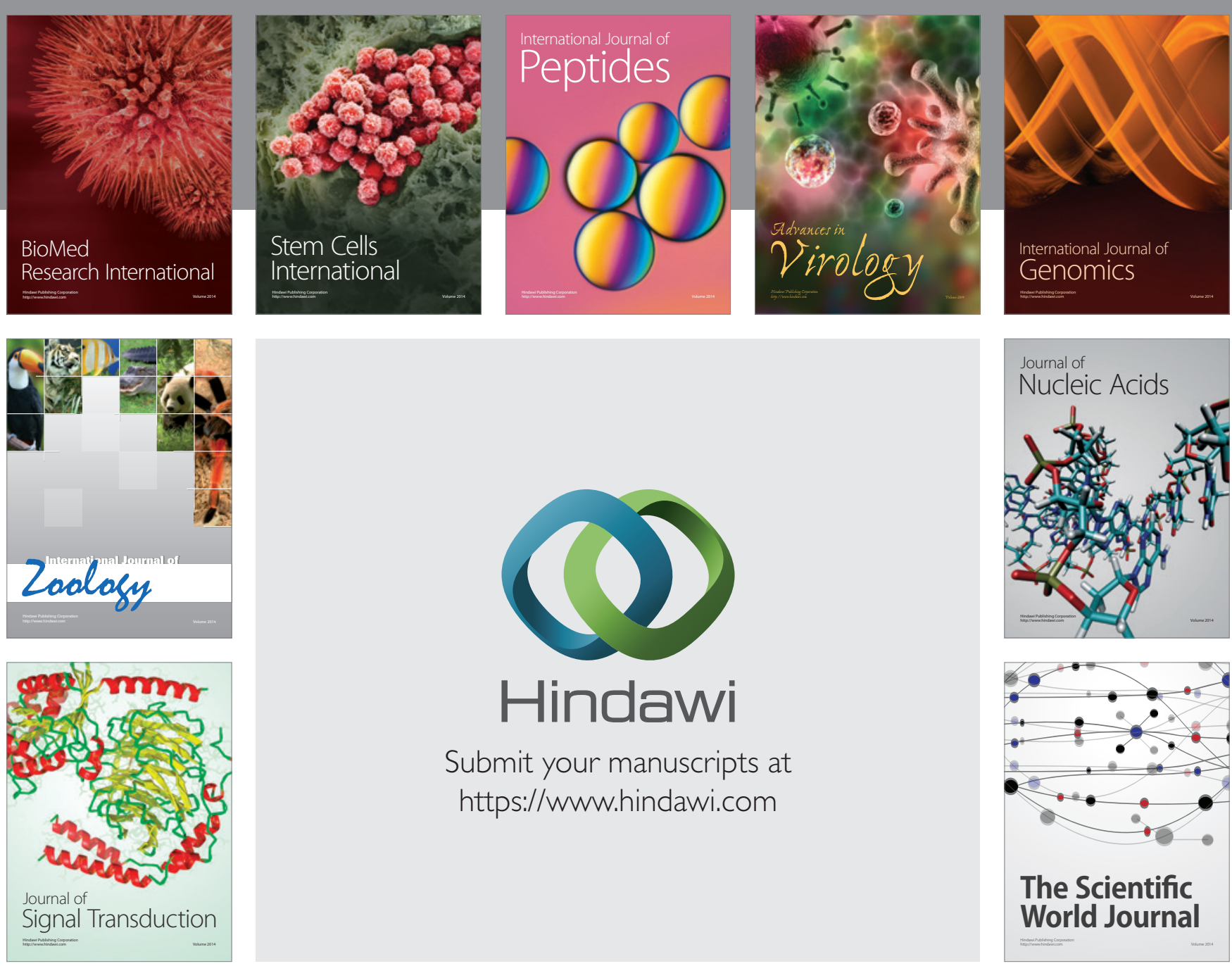

Submit your manuscripts at

https://www.hindawi.com
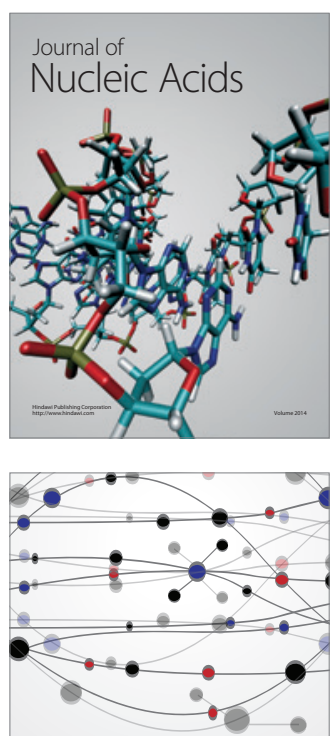

The Scientific World Journal
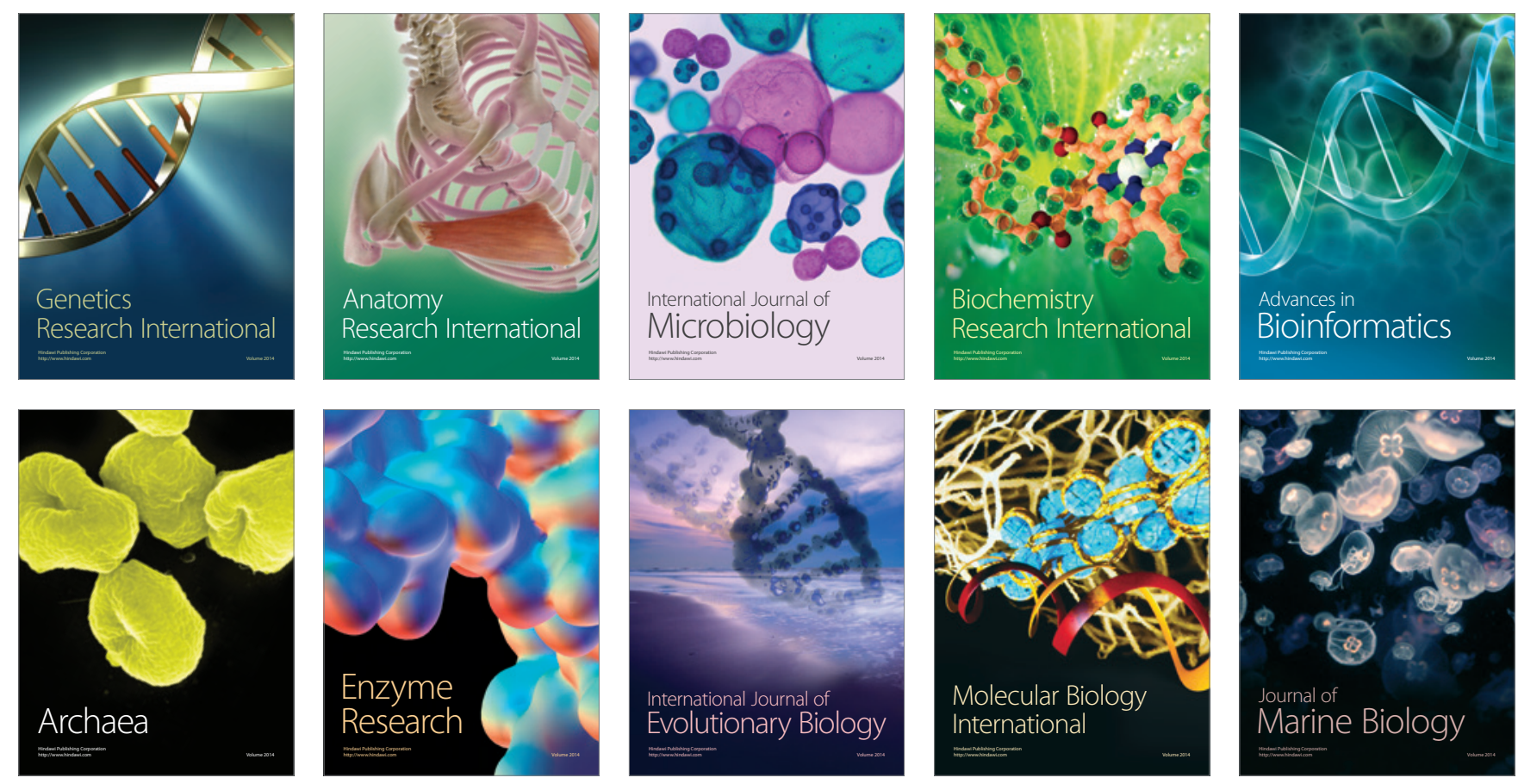